\title{
Os (des)caminhos da coleção arqueológica do Museu do Ceará e da gestão de acervos arqueológicos no Estado (1932-2012)
}

The discontinuous paths of the archaeological collection of the Museum of Ceara and the cultural management of archaeological collections in the State (1932-2012)

\author{
Cristina Rodrigues Holanda* \\ Maria Conceição Soares Meneses Lage**
}

\author{
Palavras-chave: \\ Museu \\ Arqueologia \\ Gestão de Acervos
}

Keywords:

Museum

Archeology

Collection Management

\begin{abstract}
Resumo: A pesquisa realizada teve por objetivo analisar os processos de formação e preservação da coleção arqueológica do Museu do Ceará, bem como os seus desmembramentos para a formação de outras coleções, como a do Museu do Instituto do Ceará e o Instituto de Antropologia do Ceará, buscando compreender como o tratamento dado para um acervo específico pode ajudar a pensar os próprios (des)caminhos da gestão cultural de coleções arqueológicas no território cearense, bem como pode contribuir, na atualidade, para o desenvolvimento dos trabalhos arqueológicos no Brasil.
\end{abstract}

\begin{abstract}
The objetive of the research was to analyze the processes of formation and preservation of the archaeological collection of the Museum of Ceará, as well as its dismemberment for the formation of other collections, of the Instituto do Ceará and the Institute of Anthropology of Ceará, trying to understand how the treatment given to this specific collection can help us to think about the discontinuous paths of cultural management of archaeological collections in the territory of Ceará, as well as contribute to the development of archaeological works in Brazil.
\end{abstract}

Recebido em 28 de maio de 2019. Aprovado em 07 de agosto de 2019.

\section{Introdução}

O Museu do Ceará completou 87 anos de existência, sendo a segunda unidade museológica oficial do Estado, criada em Fortaleza, no ano de 1932. Desde então, foi gerenciado por 16 diretores, passou por seis sedes distintas até chegar ao endereço atual, possuiu três grandes mantenedores e três denominações (HOLANDA, 2005).

Embora conhecido como um "museu de História", desde a sua fundação, a instituição sempre apresentou um acervo muito diversificado, com coleções de numismática, mobiliário, iconografia, indumentária, biologia, paleontologia, etnografia, arqueologia, entre outros, contabilizando hoje mais de 10 mil peças. Esse acervo bastante variado foi resultado, sobretudo, de inúmeras doações de particulares e instituições, com algumas compras pontuais realizadas pelo governo estadual.

A coleção arqueológica do Museu do Ceará atualmente conta com pouco mais de 2 mil peças, entre instrumentos líticos (polidos e lascados), artefatos malacológicos e cerâmicos. Formou-se desde 1932, ganhou maiores dimensões nos anos 1950, mas sofreu algumas perdas na década de 1960, em virtude das permutas de acervo entre o Museu e o Instituto de Antropologia da Universidade do Ceará.

Apesar da sua representatividade, seja em termos numéricos, de "tipologias" e de procedência

\footnotetext{
* Presidente da Fundação Memorial Padre Cícero. Mestre em História Social pela Universidade Federal do Ceará (UFC) e Especialista em Arqueologia Social Inclusiva pela Universidade Estadual do Cariri (URCA). E-mail: <crisrholanda@gmail.com>.

** Doutora em Arqueologia, Antropologia e Etnologia (Université Paris 1, Panthéon-Sorbonne, 1987/1990). Mestra em Arqueologia (Diplome D’études Aprofondés - Université de Paris I, Panthéon Sorbonne, 1986/1987). Especializada em Arqueologia pela Universidade Federal do Piauí (UFPI) (1983/1984) e Graduada em Química (Licenciatura e Bacharelado) pelas Faculdades de Filosofia, Ciências e Letras Oswaldo Cruz (São Paulo, 1980). É pesquisadora e conselheira científica da Fundação Museu do Homem Americano (desde 1986), e professora Titular da UFPI. E-mail: <meneses.lage@gmail.com>.
} 
(visto que os artefatos foram coletados em diferentes localidades do Ceará), essa coleção arqueológica não havia sido estudada em uma perspectiva histórica, ou seja, nos seus processos de formação e desmembramento, bem como em uma perspectiva preservacionista, esta que, segundo Cristina Bruno (2013/2014), compreende procedimentos de salvaguarda (conservação, documentação e armazenamento), pesquisa e divulgação (exposições, publicações e outras ações culturais). Esses procedimentos se configuram como pistas acerca dos (des)caminhos da Arqueologia no Ceará e podem ajudar as instituições que cuidam da gestão cultural de outros acervos museológicos do Estado a repensar o seu papel no desenvolvimento da Arqueologia Brasileira.

A pesquisa aqui apresentada percorreu, além de todos os estudos já realizados sobre o Museu do Ceará, o Livro de Tombo, fichas de inventário, catálogos e outras publicações institucionais, além de matérias de jornais, do período de 1932 a 2012, compiladas pelo Museu, que tratam desse acervo.

\section{Os primórdios da Arqueologia no Brasil e no Ceará}

Alguns viajantes europeus assumiram o papel de cronistas e naturalistas, transitando pelo Brasil durante os primeiros séculos de ocupação colonial do território, proporcionando informações sobre a cultura material vivenciada pelos colonizadores e, sobretudo, pelos povos nativos. São eles que nos dão notícia, seja por meio da escrita e/ ou desenhos e pinturas, sobre as primeiras gravações rupestres encontradas, bem como sobre a fabricação e utilização de diversos instrumentos líticos e cerâmicos (ROCHA, 2011; LANGER, 2001).

$\mathrm{Na}$ ausência de universidades no Brasil até o período republicano, o Instituto Histórico e Geográfico Brasileiro (IHGB), criado em 1838, bem como os Institutos congêneres das províncias, seriam os grandes responsáveis pela produção do saber científico, especialmente em áreas como História, Geografia, Antropologia, Arqueologia e Paleontologia (AMARAL, 2002). As instituições museológicas inauguradas no Brasil nesse mesmo
Período Oitocentista - em especial o Museu Nacional (antigo Museu Real); Museu Paraense Emílio Goeldi e Museu Paulista - também foram muito importantes para o desenvolvimento da Antropologia, da Arqueologia, da Paleontologia e da Biologia no Brasil. Afinal, realizaram trabalhos de coleta, guarda, classificação, análise e publicação de informações sobre fósseis, espécimes da natureza e itens da cultura material das populações nativas (SCHWARCZ, 1995).

$\mathrm{O}$ Instituto (Histórico, Geográfico $e$ Antropológico) do Ceará foi fundado em Fortaleza, no ano de 1887. Antes e após a sua criação, até a década de 1950, a literatura sobre Arqueologia em terras cearenses é muito pontual, bem como o número de estudiosos é incipiente, conforme argumentam Viana e Luna (2018). Contudo, um pouco antes da inauguração do Instituto do Ceará, a capital alencarina já contava com uma Coleção de História Natural pertencente ao médico Joaquim Antônio Alves Ribeiro (1871), que gerou o Museu Provincial, mantido em parceria com o governo da Província do Ceará e o Gabinete Cearense de Leitura, sociedade literária que funcionou entre 1875 a 1886. No âmbito dessa parceria, o Gabinete deveria criar e manter, inclusive, um Instituto Histórico e Arqueológico. Em 1885, o Museu Provincial foi transferido para a Escola Normal, a pedido da Inspetoria de Educação. No ano de 1891, houve uma tentativa de transferência do acervo para o Liceu do Ceará, que não o recebeu alegando falta de condições de conservação. Dez anos depois, apenas uma parte da coleção de Joaquim Alves ainda se encontrava na Escola Normal. Por mais que a constituição desse museu não tenha logrado tanto êxito, "[...] ela demonstrou um interesse pela produção de conhecimento e a inserção da Província nos modelos científicos em voga" (VIEIRA, 2014, p. 43).

O Museu Rocha surgiu em 1894. Embora privado, recebendo minguadas ajudas oficiais, conseguiu arregimentar, até 1908, nada menos que dez mil espécimes distribuídos nas áreas de Botânica, Zoologia, Fitopatologia, Mineralogia, Etnografia e Arqueologia. Sua coleção era conhecida por vários estudiosos do país e do exterior, com os quais seu idealizador, o autodidata Francisco Dias 
da Rocha, mantinha regular correspondência, além da troca de publicações e de exemplares. Devido aos seus préstimos, chegou a ser homenageado muitas vezes, quando batizaram várias espécies novas com o seu sobrenome. O Museu Rocha foi mais bem documentado que o Museu Provincial, visto que resistiu até 1959, enquanto Dias da Rocha gozou de saúde para mantê-lo. Antônio Bezerra de Menezes, assim se referia ao empreendimento:

Aquela instituição científica não consta de mera acumulação de raridades, objetos curiosos, mas de ricas coleções sistematicamente acondicionadas e dispostas de conformidade com as regras estabelecidas nos grandes museus [...] Tudo ali está de tal forma exposto, exibindo-se admiravelmente aos olhares de todos, que atrai, surpreende e produz no visitante a mais agradável impressão. (MENEZES, 1910 apud HITOSHI, 1965, p. 227).

Além de Joaquim Alves e Dias da Rocha, outros homens de notada erudição, no Ceará, dedicaram esforços para colecionar artefatos arqueológicos e etnográficos, como Carlos Studart Filho e Thomaz Pompeu de Sousa Brasil Sobrinho, para citar os mais expressivos. Além de colecionadores, eram pesquisadores que atribuíam a confecção desses artefatos às sociedades indígenas, coloniais e pré-coloniais (MARQUES, 2012). Essas coleções particulares foram compor, posteriormente, o Museu do Instituto do Ceará, fundado nos anos 1940, e depois integrado ao Museu Histórico e Antropológico do Ceará.

\section{O Museu Histórico do Ceará (1932- 1951)}

Quando inaugurado, o então Museu Histórico do Ceará (MHC) ocupava duas salas do Arquivo Público do Estado, e ambos eram dirigidos pelo jurista e historiógrafo Eusébio de Sousa. Sua formação diferenciou-se de outras grandes instituições museológicas do país, como o Museu Histórico Nacional (MHN) e o Museu Paulista (MP), que incorporaram acervos preexistentes de outras instituições, alguns de grande valor material (prataria, louças finas, joias etc.), conquistaram mantenedores influentes no seu nascedouro e mantiveram-se, até os dias atuais, no mesmo prédio de origem.

As dificuldades financeiras pelas quais o Museu passou impediram a sustentação de muitos dos seus projetos institucionais, o que limitou suas ações de "compra", "fabricação" de peças (como esculturas e quadros) ou "coleta direta". Assim, a formação do acervo deveu-se principalmente às doações advindas de setores privilegiados da sociedade. Além de circulares e cartas enviadas a determinadas instituições e pessoas, Eusébio realizou vários "pedidos" pessoalmente e por meio da imprensa. Conseguiu ainda a nomeação oficial, não remunerada, de Agentes Auxiliares para 40 municípios do Ceará, Rio de Janeiro e Paraíba. Esses Agentes, em geral juízes de Direito e párocos, tinham a função de facilitar a localização e a doação de itens para o Museu Histórico (HOLANDA, 2005).

Observa-se que Eusébio de Sousa procurou direcionar as doações em consonância com a sua compreensão sobre as finalidades de um museu histórico, que deveria estar voltada para o vislumbre do passado glorioso do Ceará e, por extensão, do Brasil, em uma perspectiva do "culto da saudade" proposto por Gustavo Barroso ${ }^{1}$, que privilegiava as ações pretéritas relacionadas aos grandes homens e feitos da vida política, intelectual e diplomática da nação brasileira, com origens vinculadas à Europa. Nesse sentido, índios, negros e mestiços eram considerados personagens "subalternos", "inferiores" e "exóticos" da História. Essa concepção predominou no Museu do Ceará do seu nascedouro até a década de 1990 (OLIVEIRA, 2009; COSTA, 2012).

Apesar do empenho de Eusébio de Sousa, a arrecadação de objetos para o Museu Histórico acabou gerando um acervo diversificado, que muitas vezes fugiu dos parâmetros estabelecidos por ele, na medida em que alguns doadores tratavam o espaço museológico como um lugar de exibir "objetos populares" (colher de pau, berrantes, armas de cangaceiros), "fragmentos do mundo natural" (foto de gêmeas siamesas, vértebra de baleia, fósseis etc.) e "curiosidades" produzidas pelo homem (destroços de aviões, curativo de guerra, objetos líticos ou cerâmicos dos "silvícolas" etc.). 
Desse período de 1932 a 1942, não sobreviveu um Livro de Tombo (aliás, o único existente foi aberto em 1959), sequer uma listagem do acervo. Mas é muito provável, considerando seu estágio de observação no Museu Histórico Nacional e a preocupação de registrar suas ações institucionais, que Eusébio de Sousa tenha elaborado tal documento, que se perdeu. O levantamento do acervo inicial do Museu do Ceará aconteceu em razão do trabalho de Holanda (2005), que permitiu reconstruir o primeiro inventário sistematizado da instituição, como nos ajuda também a perceber as perdas que o acervo sofreu.

Eusébio recebeu alguns artefatos como cachimbos, machados polidos, vasos e urnas funerárias, remetidos por diferentes indivíduos. Alguns desses objetos pertenciam a grupos localizados fora do Ceará, mas outros foram encontrados no território cearense, a partir de escavações procedidas para construir cacimbas, em diferentes localidades. Em suma, muitas dessas peças eram encontradas fortuitamente, fato que demonstra a quase inexistência no Estado de pesquisas arqueológicas de campo, reclamadas por Studart Filho (1942) e Brasil Sobrinho (1942). Assim, os achados chegavam ao Museu sem o devido detalhamento técnico com relação ao seu local exato de recolhimento. A descrição realizada era sumária, privilegiando mais o doador do que o artefato.

Embora a visibilidade oferecida aos artefatos arqueológicos nos documentos oficiais o Museu Histórico do Ceará fosse pequena, comparada àquela dada aos objetos que se relacionavam com o "culto da saudade" proposto por Gustavo Barroso, não se pode dizer que Eusébio de Sousa as tenha desprezado. Ele mesmo chegou a doar um machado e mandou publicar, no Boletim $n^{\circ} 2$ do Museu Histórico, fotos de vasos de cerâmica achados acidentalmente após a escavação de terrenos no Crato e em Limoeiro do Norte/CE.

A vitrine de cerâmica do Museu apresenta um contraste que poderá parecer chocante aos que se distanciam da archeologia. É que ao lado de um formoso Nevers, dos famosos jarrões de decorações orientaes do Passeio
Público, dos pratos pseudo-Sévres do $2^{\circ}$ Império, trazendo em dourado as iniciaes de Pedro II e o monograma hialino de Caxias, depara-se-nos pequena malga indígena, encontrada na região do baixo-Jaguaribe, em Nova Hollanda. Trabalho em pedra, de admirável perfeição, denotando já o apuro dos nossos selvícolas na industria da pedra polida. Contraste, pois, só aparentemente chocante. (JORNAL O NORDESTE, 1934). ${ }^{2}$

Além dos doadores "leigos", existiam também intelectuais que enviaram peças para o Museu, como os membros da Sociedade Cearense de Geografia e História, que foram averiguar, em 1937, a descoberta de vasos de cerâmica indígena, envolvidos por tecido de palha de palmeira, contendo alguns ossos fossilizados, encontrados por um campônio na Pedra da Canastra (município de Sobral/CE). Constatado e recolhido o achado, ele foi depositado no Museu Histórico do Ceará. No entanto, esses e outros achados que chegavam eram considerados mais sob o prisma da Antropologia, do que da Arqueologia e da Paleontologia.

A Antropologia, no início do século XX, começou a situar os artefatos indígenas dentro de um enquadramento relativista, censurando a concepção universalista e evolucionista da cultura, dominante em meados do século XIX, para propor um entendimento etnográfico centrado na ideia de "culturas" no plural. Por este enfoque, as peças deveriam ser estudadas:

[...] a partir de suas funções ou significados em totalidades sociais e culturais [singulares]. Importava, assim, pensá-los no contexto do cotidiano das sociedades ou culturas estudadas, enquanto demarcadores simbólicos de identidades e processos socioculturais, ou ainda, como partes significativas de processos rituais ou cosmologias. (GONÇALVES, 1999, p. 22).

Eusébio de Sousa e os demais ofertantes dos objetos arqueológicos não pareciam considerar essas questões, quando verificamos a produção escrita desse intelectual e a organização do Museu Histórico, como também a concepção esboçada nas entrelinhas desse comentário jornalístico: 
O cemitério indígena recém-explorado veio revelar à ciência contemporânea novos aspectos para o estudo do homem cearense, ante o perfeito estado de conservação dos crânios, o volume de maxilares inferiores, o estado de fossilização de alguns e a variedade dos tecidos de palha de palmeira encontrados nas urnas funerárias. Ante a importância das questões que falam de perto à antropologia brasiliana, fazemos o seu registro, deixando aos estudiosos do assunto a sua apreciação. (JORNAL O POVO, 1937, p. 2). ${ }^{3}$

O comentário privilegia menos os artefatos que os fósseis humanos. Para quem escreveu o texto, não havia no Ceará pesquisadores especializados e os estudos antropológicos ainda estariam voltados para esclarecer a origem e o desenvolvimento dos povos, tomando como principais "documentos" não os vestígios da produção das sociedades, mas principalmente os restos mortais dos seus membros. Essa visão sobre as atribuições da Antropologia, seguramente partilhada pelos protagonistas do episódio de 1937, remonta às concepções do século anterior, quando a disciplina era entendida como um ramo das Ciências Naturais, desenvolvendo áreas (Frenologia e Antropometria) que privilegiavam a análise dos comportamentos humanos sob um prisma biológico, disputando espaço com a Arqueologia e a Paleontologia. A Etnologia, depois chamada de Antropologia Cultural, é que se ocupava dos estudos sobre as diferenças culturais, mas na perspectiva comparativa, evolucionista e hierarquizadora (SCHWARCZ, 1995).

Nas décadas de 1930-1940, ainda predominavam variadas teorias para explicar as diferenças culturais, muitas baseadas nos conceitos como "meio" e "raça". Apesar de distintos, esses conceitos tinham como denominador comum à aceitação do evolucionismo. Esse postulado previa que todas as sociedades surgiam a partir de um estágio "primitivo" - como supostamente viviam as comunidades indígenas no Brasil - e evoluíam naturalmente para patamares mais "complexos" - como as nações europeias - sendo necessário descobrir os nexos entre os diferentes povos e as leis que presidiam o "progresso" (ORTIZ, 1985).
Pensamento bem diferente do que hoje se aceita e procura seguir, ou seja, um pensamento de descolonização ou de tirar a Europa como o centro do mundo.

Presume-se que os artefatos arqueológicos que chegavam ao Museu Histórico do Ceará eram vistos pelos ofertantes como "arte primitiva", "curiosidades exóticas" ou "vestígios para o estudo antropológico", descontextualizadas dos seus locais de origem, representando um ancestral distante no espaço e no tempo ou ainda como atestados de um estágio de "evolução inferior" e, portanto, distinto da nação brasileira, que conseguira galgar certos patamares de desenvolvimento sociocultural graças às influências da civilização europeia.

Com a aposentadoria de Eusébio de Sousa, em 1942, o Museu passou por um período de "abandono", de acordo com os jornais da época, mesmo com o revezamento de quatro diretores na sua gerência, até 1951. Uma interpretação possível para esse quadro e o seu novo redirecionamento, ao ser integrado formalmente ao Instituto do Ceará, está relacionada às disputas de poder travadas no interior dessa agremiação a partir de 1937, com a morte do Barão de Studart ${ }^{4}$, fato que gerou, além da composição de uma nova diretoria, uma nova atuação do Instituto.

Há muitos indícios de que essas disputas foram encabeçadas por Pompeu Sobrinho (o segundo e último presidente perpétuo, de 19371967), culminando com o ostracismo de Eusébio de Sousa (que ocupou o cargo de Primeiro Secretário do Instituto de 1930-1937) e a criação do Museu do Instituto do Ceará, em 1940, "[...] graças aos esforços do Dr. Pompeu [Brasil] Sobrinho, verdadeiro sábio de comovedora dedicação", segundo o Jornal O Estado (1941, p. 8) .

Pelas fotografias de suas salas, percebese que esse espaço assumiu uma configuração semelhante ao Museu Histórico do Ceará, retirando dele, inclusive, vários objetos, como os achados da Serra da Canastra. De acordo com Brasil Sobrinho (1942, p. 165), eles estavam expostos "para a curiosidade do público [...] sofrendo uma irracional acomodação e uma insuficiente proteção".

Por seu turno, o Museu Histórico do Ceará, após 1937, sofreu perdas gradativas: as verbas 
oficiais que lhe eram destinadas foram escasseando; as doações foram diminuindo; e o amplo espaço na imprensa, para divulgação, também foi reduzido, enquanto aumentavam as matérias do jornal $O$ Estado acerca das doações enviadas para o Museu do Instituto, que também constam em publicações do sodalício.

Os embates geraram ainda, em 1938, a ausência de Eusébio de Sousa das reuniões ordinárias, seu afastamento da diretoria do Instituto, da Comissão de Publicação da Revista e da sua condição de membro efetivo da agremiação (1942), sendo reintegrado em outra cadeira em 1945. Após a sua aposentadoria, os diretores que se revezaram no Museu não possuíam nenhum vínculo, à época, com o Instituto do Ceará.

\section{O Museu Histórico e Antropológico do Ceará, entre dois Institutos: o Histórico e o de Antropologia (1951-1967)}

Em 1951, um acordo entre governo estadual e o Instituto Histórico, Geográfico e Antropológico do Ceará permitiu que essa agremiação de caráter particular fosse transferida para o prédio onde estava o Arquivo Público (enviado na sequência para outro endereço) e passasse a gerenciar o Museu Histórico do Ceará.

Valdelice Girão ${ }^{6}$ foi uma das funcionárias nessa nova fase e participou de um estágio no Museu Histórico Nacional. Organizou, a partir dessa experiência, o primeiro modelo de Ficha de inventário dos objetos musealizados e o primeiro Livro de Tombo do Museu (1959). Ela afirma que encontrou o acervo coligido por Eusébio de Sousa muito deteriorado. Por isso, novos itens sobre a história cearense e do Nordeste foram adquiridos (HOLANDA, 2006).

Do Museu do Instituto do Ceará vieram artefatos coletados por Pompeu Brasil Sobrinho. Outros foram comprados pelo Estado, em 1953, provenientes do Museu Rocha. Entre 1958 e 1959, uma coleção da Escola Normal Justiniano de Serpa foi também remetida, em razão da reestruturação do educandário, que culminou com sua transferência do centro de Fortaleza para o bairro de Fátima e a mudança de sua designação para o Instituto de Educação do Ceará (OLIVEIRA, 2008). Essa coleção foi tombada pelo Instituto do Patrimônio Histórico e Artístico Nacional (IPHAN) em 1941 e continua sendo a única coleção tombada do Ceará. Era composta por cerâmica indígena, arcos e flechas, enfeites e machados de pedra, entre outros objetos, conforme informações do site da autarquia. "Era" porque hoje ela não está mais organizada da forma como foi tombada, visto que seus itens estão dispersos dentro de outras coleções do Museu.

Todas essas novas aquisições acabaram dando uma feição diferenciada à referida instituição, que reabriu em 1955, com um novo nome: Museu Histórico e Antropológico do Ceará. O jurista Raimundo Girão tornou-se o novo diretor, imprimindo sua marca a essa instituição pelos 20 anos subsequentes, mesmo quando alternou a direção com outros consórcios do Instituto do Ceará. Mas houve também a influência de Pompeu Brasil Sobrinho, que nessa época era presidente do Instituto e já possuía uma vasta produção intelectual nas áreas de Arqueologia e Antropologia. Influência percebida com o acréscimo do novo acervo, do termo "Antropológico" ao nome da instituição e a tentativa de criar "salas temáticas" de exposição. Como recorda Valdelice Girão (2006),

[A classificação dos] objetos históricos eram sob a orientação do Raimundo Girão, que dizia: 'Leia isso, veja isso'. Já a classificação do material arqueológico era orientada por Pompeu Sobrinho [...] Ele chegou a fazer um modelo de ficha para o Museu, principalmente para a coleção de artefatos líticos. Depois eu ia preenchendo as fichas com outra colega. Nós íamos preenchendo depois que a peça já tinha sido pesada e tal [...] Todo dia era sempre o mesmo trabalho: papel, bater à máquina. Já o Prof. Dias da Rocha ajudou pouco, porque ele já era velhinho quando o Instituto comprou sua coleção lítica. Ele dizia: Essa peça é de tal lugar, aquela é de tal parte. Pode ser até que não fosse real. Mas eu acho que uma pessoa que passou a vida todinha trabalhando com isso não podia esquecer!? O General Studart, que além de indigenista, era historiador [...] me tratava muito bem. 
Foi ali que eu aprendi muito [...] Eu ia lendo e a convivência com as pessoas do Instituto me enriquecia. (apud HOLANDA, 2006, p. 51-55).

Percebe-se que o acervo arqueológico musealizado era resultado de coleções préexistentes, que parecem ter sido formadas por doações, permutas, achados fortuitos, mais do que pela pesquisa intencional em campo. Vinham de várias partes do Brasil. Faltava, ainda, uma instituição habilitada para dar suporte técnico e financeiro para esse tipo de pesquisa no Ceará, como reclamava Pompeu Brasil Sobrinho (1942). Tal fato também demonstra a escassez de prospecções arqueológicas, especialmente promovidas pelo próprio Museu. Assim, os achados continuavam a chegar apenas com o nome da localidade de onde procediam, mas sem o devido detalhamento técnico com relação à data, forma de coleta e contexto de origem. Entretanto, a descrição física dos artefatos ganhou mais atenção. Cada peça recebeu uma numeração e uma ficha, onde suas dimensões e peso eram registrados.

Por meio do Guia do Visitante (1960), percebemos a organização de cinco salas de exposição: Sala do Sertão, Sala do Índio, a Sala da Cidade; Sala Eusébio de Sousa e Sala dos Generais. Era na Sala do Índio que ficava a coleção arqueológica, composta por artefatos líticos (polidos, em sua maioria), cachimbos, amuletos e igaçabas. Esse formato consolidou-se em 1957, quando o Museu estava no prédio da Avenida Visconde do Cauype, $n^{\circ} 2341$ (atual FEAAC/UFC, na Avenida da Universidade). O Instituto do Ceará ficava no andar superior e o Museu no térreo.

Contudo, apesar das tentativas de tematizar as salas, algumas ainda mantiveram características do "culto da saudade", ou seja, uma "relação fragmentada e romântica do passado" (OLIVEIRA, 2009 , p. 141), sem conseguir em muitos casos estabelecer um texto tridimensional temático ou cronológico com os objetos.

Em 1957, como parte do processo de construção da primeira universidade cearense, foi criado o SAUC (Serviço de Antropologia da Universidade do Ceará). O projeto foi elaborado por Pompeu Brasil Sobrinho. Houve um arranjo institucional entre a universidade e o Instituto do Ceará. Enquanto a Universidade ficou responsável pela manutenção financeira de funcionários e projetos, o Instituto do Ceará abrigou o SAUC em sua sede, juntamente com o Museu Histórico e Antropológico do Ceará.

O Serviço de Antropologia, com a realização de cursos profissionais, foi a primeira tentativa formal de criar e consolidar um novo "campo" científico no Ceará. Em virtude do seu bom desempenho, logo foi transformado em Instituto de Antropologia (1958). Pompeu Brasil Sobrinho ficou na Presidência dos dois Institutos, o de História e o de Antropologia, concomitantemente, até 1966, quando se afastou para tratamento de saúde, vindo a falecer. Para Oliveira (2009), o intelectual investiu maiores esforços na nova instituição, o que explicaria a grande ascendência de Raimundo Girão sobre a condução do Instituto e do Museu Histórico e Antropológico do Ceará.

As atividades docentes do Instituto de Antropologia eram feitas tanto por professores contratados, como por membros do Instituto do Ceará, entre os quais Florival Seraine e Carlos Studart Filho. Esse último, aliás, em virtude das diferentes frentes de pesquisa em que pode atuar com o apoio da Universidade, tais como a Arqueologia, recebeu o Prêmio Gustavo Barroso, em 1965. Ao mesmo tempo em que eram realizados cursos de formações, eram promovidas pesquisas de campo, que utilizavam como instrumento de divulgação o Boletim de Antropologia.

O Instituto de Antropologia foi formando um acervo museológico próprio, também inventariado por Valdelice Girão, que incluiu as coleções Arthur Ramos; Luiza Ramos; Benevides; Arqueologia e PréHistória; entre outras. Sabe-se que as primeiras foram compradas pela Universidade do Ceará em 1957. No caso da coleção de Arqueologia e Pré-História, ela foi formada a partir das pesquisas incentivadas no âmbito do próprio Instituto de Antropologia, mas também de permutas. Cada coleção contava com um curador. Esse acervo, ora chamado pela imprensa de Museu Antropológico, ora de Museu do Instituto de Antropologia e/ou Museu de Arte Popular (VIEIRA, 
2014), ficou ocupando apenas uma sala do edifício onde estava o Instituto do Ceará e o Museu Histórico $e$ Antropológico. Segundo Valdelice Girão, as coleções do Instituto de Antropologia ficaram “[...] organizadas em prateleiras, mas não para exposição. Ficaram em armários grandes [...]. Esse Acervo era guardado para estudo e para quando o Instituto de Antropologia tivesse um prédio, para formar um museu" (GIRÃO, 2006 apud HOLANDA, 2006, p. 46-47). Tal museu foi aberto ao público em janeiro de 1967, na Avenida Visconde do Cauype (Avenida da Universidade), onde atualmente funciona a Casa Amarela Eusélio Oliveira.

Com a Reforma Universitária promovida em fins de 1968 no país (Lei Federal no 5.540/68), o Instituto de Antropologia foi absorvido pelo Departamento de Ciências Sociais da Universidade, atrelando ao Departamento o antigo acervo coligido, como a contratação de novos docentes e o afastamento de antigos professores. Esse acervo museológico ficou no referido Departamento até 1981, ano de sua transferência para a Casa de José de Alencar (CJA) (VIEIRA, 2014), onde foi reaberto com o nome de Museu Arthur Ramos. Foi lá, consultando as fichas de inventário e o Livro de Tombo do Museu do Instituto de Antropologia, por intermédio da museóloga Márcia Alencar, que se descobriu uma permuta de objetos arqueológicos do Museu Histórico e Antropológico do Ceará por peças da Coleção Benevides, composta por uniformes militares, armas, bustos, porcelanas, cadeados, dobradiças, chaves, santos, ex-votos etc. São objetos oriundos de Juazeiro do Norte, relacionados com a cidade, o cangaço e a figura do Padre Cícero, arregimentados pelo colecionador particular Aldenor Jayme Alencar Benevides (OLIVEIRA, 2015).

\section{A Secult como mantenedora do Museu Histórico e Antropológico (1967-1990)}

Com a criação da Secult (Secretaria Estadual da Cultura), a primeira do Brasil, por meio da Lei no 8.541/66, o Museu Histórico e Antropológico do Ceará saiu da sede e da subordinação do Instituto do Ceará e passou novamente para a administração direta do Estado. Embora o primeiro Secretário da pasta fosse Raimundo Girão, os novos diretores do Museu não eram seus companheiros de agremiação.

Célsio Brasil Girão é incumbido da missão por curto período (1967-1971). De 1971 a 1990, foi designado o Sr. Osmírio Barreto, odontólogo, como o novo Diretor. Uma das primeiras modificações realizadas por ele foi a reorganização das salas de exposição. Duas delas permaneceram com os nomes anteriores: Sala da Cidade e Sala Eusébio de Sousa. Outras três mantiveram as mesmas temáticas, mas com novas denominações: a Sala do Índio passou a ser Sala Pompeu Sobrinho; a Sala do Sertão tornou-se Sala do Vaqueiro; e a Sala dos Generais virou Sala das Armas. Surgem outros quatro recintos: da Abolição; Capistrano de Abreu; Folclore; e Dias da Rocha.

Assim como na sua produção escrita, Barreto parecia quase não se preocupar, na organização dos espaços, em estabelecer relações temáticas ou cronológicas entre os objetos, apesar da denominação de cada espaço. Artefatos arqueológicos, por exemplo, foram expostos nas Salas: do Indio (depois Pompeu Sobrinho); Dias da Rocha; e Sala do Folclore.

Nesse sentido, os três grandes gestores que o Museu teve até então - Eusébio de Sousa, Raimundo Girão e Osmírio Barreto - cada um com suas particularidades, tiveram em comum: o uso de práticas expositivas que nos remetem à tradição dos antiquários; discursos em prol do nacionalismo; a folclorização da cultura popular; e a compreensão do Museu como instituição educativa (OLIVEIRA, 2009).

Na direção de Osmírio Barreto não há indícios de grande ampliação do acervo, seja por compra ou doações, muito menos por coletas via pesquisas de campo, cujo estímulo e resultados, no Ceará, passaram a ser atribuição quase exclusiva da Universidade. Mas um segundo modelo de ficha de inventário foi produzido, com um maior número de campos, que geravam um volume maior de informações e, ainda, uma nova numeração das peças. Essa documentação museológica possivelmente foi organizada pelo museólogo Henrique Barroso, que trabalhava no Museu 
Histórico e Antropológico dessa fase, embora muitas fichas tenham a assinatura de Barreto (RUOSO, 2009).

\section{O Museu do Ceará no Palacete Senador Alencar (1990-2012)}

Em 1990, na gestão de Violeta Arraes à frente da Secult, decidiu-se restaurar o Palacete Senador Alencar, deslocando para lá o Museu do Ceará. A nova denominação, sem os adjetivos "Histórico" e "Antropológico" buscava refletir a diversidade tipológica do acervo, os novos temas de exposição, as atividades que passou a organizar para o público, bem como a formação interdisciplinar do seu quadro técnico, especialmente de consultores contratados (museólogos, arquitetos, antropólogos, restauradores, arqueólogos, paleontólogos), apesar do predomínio, até hoje, dos historiadores, tanto em sua direção, como nos trabalhos técnicos rotineiros do Museu.

De 1990 a 1998, aconteceu, simultaneamente, a restauração do edifício e das peças, bem como um novo processo de catalogação, conduzido pela historiadora Gisete Aguiar Coelho Pereira, a confecção de um terceiro modelo de ficha de inventário, agora preenchido à mão (antes tudo era datilografado). No caso da coleção arqueológica, o trabalho de catalogação foi supervisionado pela antropóloga Maria Sylvia Porto Alegre et al. (1994). O material lítico, por exemplo, passou por uma intervenção, já que em épocas anteriores era exposto amarrado com arame não galvanizado (COSTA, 2012).

A reabertura do Museu aconteceu com várias mostras temporárias, que não apresentavam o seu acervo, como foi o caso das muitas exposições de arte contemporânea. A instituição ganhou sua primeira reserva técnica, uma Associação de Amigos e um Núcleo Educativo entre 1996-1998 (MORENO, 1998; PASSOS, 2011).

Foi somente nesse último ano a inauguração da primeira exposição de longa duração no Palacete Senador Alencar, intitulada Terra da Luz e CearáMoleque. Que história é essa?. Assinada pela renomada arquiteta carioca Gisela Magalhães, era composta por vários módulos que exibiam o acervo do Museu do Ceará de forma temática e problematizadora, que fugia de uma perspectiva linear da História, lembrando um grande labirinto construído no andar superior do prédio. Dentre esses módulos, estava a sala Indígenas Cearenses, que se mesclava à Paleontologia no Ceará, onde era possível visualizar fósseis, objetos etnográficos e arqueológicos, um painel pintado por índias Tremembé, a imagem e a escrivaninha de Pompeu Brasil Sobrinho. Além de fazer referências ao pretérito, a exposição levantava, por meio de textos e imagens, questões como a diversidade de povos indígenas no Ceará, a demarcação de suas terras e a luta do Movimento dos Trabalhadores Rurais Sem Terra (MST). Intrigante é que, apesar de o módulo ser denominado como "Indígenas Cearenses", grande parte dos objetos era proveniente de outras partes do território nacional, com especial destaque para a tribo Karajá de Goiás. Foi composto também do que sobreviveu da coleção Pompeu Sobrinho, recebendo um trato expográfico que, em grande parte, se resumia à apresentação de conjuntos de artefatos semelhantes entre si (COSTA, 2012).

A predominância de instrumentos polidos no Museu do Ceará, desde a década de 1930, somente foi rompida em 1999, quando o alemão Georg Hussong doou uma coleção de líticos lascados coletados no litoral cearense. A presença desse material, até então, "se restringia a quatro instrumentos, sendo duas pontas de projétil, uma lesma e um raspador circular" (MARQUES, 2012, p. 259), enquanto os artefatos polidos sempre impressionaram por sua variedade: machados (com orelhas, reentrâncias, sulcos), quebra-cocos, mãos-de-pilão, pilões, enxós, picaretas, cinzeis, cunhas, percutores, martelos, amoladores, bolas de boleadeira, tembetás, adornos e outros.

O acervo cerâmico, a maior parte de procedência Tupiguarani, também teve o início da sua formação na década de 1930, mas possui poucos exemplares, que foram documentados a pedido do arqueólogo André Prous. Em 2002, houve uma das últimas doações dessa tipologia: uma vasilha cerâmica doada ao Museu pelo IPHAN, retirada fortuitamente no território de uma comunidade indígena Anacé (CE). 
Entre 2000 a 2008, um quarto modelo de ficha de inventário foi elaborado, sem descartar os três anteriores. Os objetos foram mais uma vez numerados. Em muitos casos, as numerações antigas eram "exageradas", tomando uma área central dos artefatos, principalmente os líticos polidos, com algarismos muito grandes, às vezes com quase 10 $\mathrm{cm}$ de comprimento. A última numeração passou a ser mais discreta, mas não apagou os registros anteriores. Por isso, há peças com até quatro números distintos. A citada coleção foi recatalogada em 2006 sob a supervisão da arqueóloga Marcélia Marques, que intermediou uma nova doação de Georg Hussong, de líticos lascados e adornos de material malacológico, coletados no litoral cearense pelo doador.

Nessa ocasião, um projeto aprovado pelo Programa BNDES Cultural financiou a compra de equipamentos para a reserva técnica (de controle de umidade do ar e combate à proliferação de agentes biológicos), que também ganhou armários de aço inoxidável, com gavetas e prateleiras móveis, montados sobre plataformas deslizantes, que permitem a sua compactação, respeitando as dimensões dos objetos. Até então, todas as coleções eram guardadas em estantes de aço abertas ou, como no caso dos objetos líticos polidos, em caixotes de madeira, onde ficavam amontoados uns sobre os outros, sem nenhum material de isolamento.

No ano de 2005, sob a coordenação do paleontólogo Celso Lira Ximenes, aconteceu a transferência do acervo sobrevivente do Gabinete de Ciências do Instituto de Educação para o Museu do Ceará. Esse acervo estava encerrado em uma sala fechada, com indícios claros de que não vinha sendo manuseado há anos. Foram encontrados materiais zoológicos, botânicos, geológicos, paleontológicos e arqueológicos. Muitos itens eram oriundos do Museu Rocha, comprovados por meio das etiquetas, recipientes e identificações usadas pelo naturalista, fotografias de época e informações do Boletim do Museu Rocha. Principalmente nos artrópodes, verificaram-se números e nomes de outras coleções, com as quais Dias da Rocha realizava permutas. Esse acervo é, sem dúvida, a coleção científica mais antiga do Ceará (TELLES; NOJOSA, 2009).
Nesse ínterim foram inauguradas várias exposições temporárias e outra de longa duração: Ceará: uma história no plural (janeiro de 2008). A exposição anterior, Terra da Luz e Ceará-Moleque. Que história é essa?, foi aos poucos modificada durante os sete anos da gestão de Régis Lopes (SAMPAIO, 2011). Um dos seus novos módulos foi Povos indígenas: entre o passado e o futuro, onde foi priorizada a apresentação do material arqueológico, selecionado por Marcélia Marques. Com relação a esse módulo, Camila Wichers, ao analisar essa e outras exposições de Arqueologia no Brasil, em exibição na época de realização do seu doutoramento, assim se pronuncia:

Mesmo com algumas lacunas e
incongruências na apresentação
das peças [...] o que faz com que os
objetos assumam por vezes um caráter
metafórico na exposição, acreditamos
que esse é um caminho a ser trilhado
e aprimorado para a musealização
de acervos arqueológicos em museus
históricos, fazendo com que essas
evidências sejam inspiradoras para
reflexões sobre o presente. (WICHERS,
2010, p. 287).

Entre os títulos editados na Coleção Outras Histórias, surgida no Museu, em 2001, destacam-se: 1) Materiais e saber na arte rupestre, de Marcélia Marques (2009), com apresentação de Conceição Lage, um estudo introdutório sobre a coleção arqueológica em análise, além de uma apresentação das pesquisas em sítios cearenses com pinturas rupestres e uma análise comparativa da arte pré-histórica e a pintura realizada pelas índias Tremembé (CE); 2) A coleção Dias da Rocha no Museu do Ceará (2009), de Felipe Telles e Maria Diva Nojosa, resultado da catalogação do acervo Dias da Rocha, que foi amealhado em 2005, junto ao Instituto de Educação.

Para documentar o maior número de peças por meio do Catálogo do Museu do Ceará, de 2012, foi apresentado não somente o que ficava em exposição, mas também o que estava em Reserva Técnica. Assim, a coleção etnográfica foi fotografada no Catálogo como se fizesse parte do módulo Povos indígenas, embora na exposição tenham sido 
exibidos apenas os artefatos arqueológicos e objetos indígenas de entrada recente no Museu, como o painel pintado pelos Tremembé e artefatos dos Tapeba (CE), matérias de jornal e mapas. A coleção arqueológica ganhou destaque no Catálogo, com texto de Marques e 21 páginas de registro fotográfico (HOLANDA; SABINO, 2012).

A produção desse Catálogo, dentro da série Museus Brasileiros, foi um dos produtos mais recentes e importantes da instituição. Afinal, tratase de uma publicação de longa trajetória, que se tornou referência para o setor museológico nacional, em virtude da sua qualidade técnica de excelência, ampla circulação nas instituições culturais do País e seu grande volume de páginas.

\section{A coleção arqueológica do Museu do Ceará: limites e possibilidades}

A Secult anunciou concurso público em 2018. Foram ofertadas vagas para 18 diferentes áreas do saber, assim como a de Analista de Cultura, para candidatos de qualquer formação. Nenhuma delas destinada especificamente para arqueólogos.

Entre as sete unidades museológicas mantidas por esta Secretaria, apenas o Museu do Ceará abriga uma coleção arqueológica; todavia, numerosa, diversificada, além de antiga. Ao todo são 1.387 artefatos líticos polidos, 562 líticos lascados, 127 cerâmicos (77 cachimbos, 36 vasilhas de diferentes formas, 11 rodas de fuso, três urnas funerárias, além de muitos fragmentos) e alguns adornos feitos de material malacológico (MARQUES, 2012). Nunca houve um arqueólogo no seu quadro técnico. Apenas consultores colaboraram pontualmente na catalogação ou com cursos introdutórios ao tema para os servidores do Museu.

Além disso, a Secult possui uma Coordenação que define as políticas públicas para o patrimônio cultural do Estado. Como não há um arqueólogo em seu quadro, fica evidente que todas as demandas relativas ao patrimônio arqueológico ficará - em um Estado que possui muitos sítios mapeados e por descobrir, como também coleções arqueológicas em museus públicos e particulares - a cargo apenas da Superintendência do IPHAN no Ceará, com um número inexpressivo de profissionais da área.

A despeito do aumento considerável de cursos de graduação e pós-graduação em Arqueologia no país, na última década, e da demanda represada no Ceará, seja para atuar em instituições públicas preservacionistas ou na chamada "Arqueologia de contrato", as universidades locais ainda não oferecem formação específica nessa área, de modo sistemático, tampouco possuem um número significativo de profissionais habilitados. Existem institutos particulares e iniciativas públicas importantes como o Núcleo de Arqueologia e Semiótica da Universidade Estadual do Ceará (NARSE/UECE), que surgiu em 1993 com a sigla NHASC (Núcleo de Arqueologia e História do Sertão Central (NHASC); o Núcleo de Estudos em Etnologia e Arqueologia; e o Instituto de Arqueologia do Cariri Dra. Rosiane Limaverde, vinculado à Universidade Regional do Cariri (URCA). No entanto, ainda é necessário um investimento mais robusto, como nos tempos do Instituto de Antropologia da (hoje) Universidade Federal do Ceará. Essa necessidade de maiores investimentos em Arqueologia impacta os museus cearenses que possuem coleções arqueológicas.

Como apontamos ao longo do artigo, a quase totalidade da referida coleção dessa unidade museológica, apesar da sua representatividade, não é oriunda de prospecções conduzidas por especialistas em sítios previamente identificados, onde se adotam procedimentos rigorosos quanto à escavação, retirada, identificação e exame dos vestígios. Muitos desses artefatos ou seus fragmentos chegaram direta ou indiretamente, ao Museu do Ceará, a partir de descobertas "acidentais", no momento de construção de obras públicas ou particulares. Diretamente, quando o "descobridor" encaminhou o "achado" para o Museu, ou indiretamente quando o remetia para estudiosos que desenvolviam uma prática colecionista, como Dias da Rocha, Pompeu Brasil Sobrinho e Studart Filho, cujos acervos posteriormente migraram para o Museu do Ceará. A catalogação e o acondicionamento das peças também não seguem rigorosamente as normativas indicadas pelo órgão fiscalizador, o IPHAN. 
Isso não quer dizer que as peças arqueológicas estejam desprovidas de informações ou negligenciadas, a despeito de sabermos que a Arqueologia é uma área que ganhou autonomia recente, em terras brasileiras, apesar da legislação que protege os sítios e os achados arqueológicos no país datar de 1961 (Lei Federal no 3.924/61) e da Constituição Federal de 1988 consolidar tal proteção. Afinal, o desenvolvimento de pesquisas no âmbito do Museu do Ceará, ainda que tenha passado por momentos de descontinuidade, remonta desde a sua fundação em 1932, com a publicação de boletins, catálogos e livros, bem como o incremento de ações de salvaguarda. Porém, essas informações sobre a coleção arqueológica em questão e o seu acondicionamento não possuem o mesmo nível de detalhamento de outros acervos que são retirados do seu contexto e guardados a partir de projeto fundamentado nos procedimentos teóricos e metodológicos partilhados pela Arqueologia, a exemplo do que acontece na Reserva Técnica do Memorial Homem do Kariri, integrado simultaneamente à Fundação Casa Grande e ao Instituto de Arqueologia Dra. Rosiane Limaverde, em Nova Olinda/CE.

Diante do exposto, alguns especialistas já afirmaram que a importância da coleção arqueológica do Museu do Ceará é maior em termos didáticos, no sentido de divulgação da ciência arqueológica para o grande público, do que em termos científicos, quando se pensa no estímulo à produção acadêmica que busca inferir, a partir desses "vestígios humanos", reflexões sobre os modos de vida de determinadas populações pretéritas que já viveram no que hoje chamamos de "território cearense" ou "brasileiro".

É urgente a proposição de um Plano de Gestão desse acervo arqueológico do Museu do Ceará. No Plano Museológico ${ }^{7}$, elaborado em 2017, falta ainda esse olhar específico para a preservação de cada coleção, que inclui não apenas a salvaguarda do material, mas sua pesquisa e comunicação. Por isso, o Plano de Gestão deve envolver arqueólogos e profissionais afins, mas também a sociedade, para o desenvolvimento de pesquisas acadêmicas e ações de educação patrimonial, considerando o potencial que a coleção inegavelmente possui para a difusão da Arqueologia como ciência, em um Estado onde esse campo do saber é pouco conhecido.

Esse Plano de Gestão deve estar atento ao conjunto, elaborado recentemente pelo IPHAN, de dispositivos normativos dedicados à gestão dos acervos arqueológicos, no ano de 2016, como as Portarias $\mathrm{n}^{\circ} 195,196$ e 197, como também aos protocolos já elaborados por instituições de salvaguarda e pesquisa que possuem uma expertise reconhecida no trato de coleções arqueológicas, procurando estabelecer intercâmbios que favoreçam a adoção de procedimentos de excelência, que nem sempre significam, necessariamente, a adoção de tecnologias caras. Para tanto, não é preciso ir tão longe. No sul do Ceará, o já citado Instituto de Arqueologia Dra. Rosiane Limaverde, embora jovem, tem muito a contribuir, bem como o Museu do Homem Americano (Piauí), entre outros parceiros no território nacional, cujas coleções são acompanhadas de farta documentação sobre tipos e metodologia das escavações arqueológicas realizadas, desenhos e fotografias de cada nível e setor evidenciado nas prospecções, fichas documentais, amostras de sedimento, cadernos de campo, relatórios das investigações, numeração das etiquetas, tipo de acondicionamento e transporte, banco de imagens etc.

Esse Plano de Gestão será mais bemsucedido se for fundamentado tanto nos pressupostos de uma Arqueologia Social Inclusiva defendida na tese de doutoramento de Mendonça (2006), como nos parâmetros de uma Ciência Cidadã, conforme European Citizen Science Association (ECSA, 2015), no que ambos os campos possuem em comum: o diálogo entre especialistas e as comunidades, na construção e difusão do conhecimento cientificamente conduzido e na gestão de territórios e serviços.

\section{Notas}

1 Cearense que atuou como advogado, professor, político, folclorista, contista, ensaísta, romancista e museólogo. Foi eleito para a Academia Brasileira de Letras em 1923. Foi o primeiro diretor do Museu Histórico Nacional, de 1922 a 1930, retornando em 1932 e permanecendo até 
1959. Criou o primeiro Curso de Museologia do Brasil (1932) e um tratado sobre a área (MAGALHÃES, 2004).

2 O contraste na cerâmica do Museu, conforme reportagem do Jornal O Nordeste, de 5 de abril de 1934. Os trechos de documentos e reportagens, como essa, foram mantidos com sua grafia original; portanto, quaisquer desvios à norma culta devem ser desconsiderados.

3 Importantes documentos antropológicos. A Serra da Canastra no município de Sobral e o cemitério indígena ali descoberto, texto publicado em Jornal O Povo, de 18 de novembro de 1937.

4 Foi um dos sócios fundadores do sodalício, tornandose "presidente perpétuo" da instituição, que passou a ser conhecida como a "Casa do Barão".

5 Em prol da cultura cearense. A obra do Instituto do Ceará em 55 anos de existência, segundo publicação do Jornal O Estado, 29 de agosto de 1941.

6 Trabalhou no Museu entre 1951-1967. Esse foi o seu primeiro emprego, antes de se graduar em História e começar uma carreira acadêmica.

7 O Plano Museológico é compreendido como ferramenta básica de planejamento estratégico, indispensável para a identificação da vocação da instituição museológica quanto à definição, ao ordenamento e à priorização dos objetivos e ações de cada uma de suas áreas de funcionamento (BRASIL, 2018).

\section{Referências}

AMARAL, Eduardo Lúcio Guilherme. Política e Intelectuais no Instituto do Ceará. Orientador: Estefânia Knotz Canguçu Fraga. 2002, 181 f Dissertação (Mestrado em História) - Programa de Pós-Graduação em História História, Pontifícia Universidade Católica, São Paulo, 2002.

BRASIL. Lei Federal $n^{\mathbf{o}} \mathbf{1 1 . 9 0 4 / 2 0 0 9}$. Institui o Estatuto de Museus e dá outras providências. Disponível em: http://www.planalto.gov.br/ ccivil_03/_ato2007-2010/2009/lei/111904.htm. Acesso em: 10 dez. 2018.

BRASIL SOBRINHO, Thomaz Pompeu de Sousa. Os crânios da gruta da Serra da Canastra. Revista do Instituto do Ceará. Tomo 56. Fortaleza: Imprensa Oficial, 1942, p. 1- 43.

BRUNO, Maria Cristina Oliveira. Musealização da Arqueologia. Caminhos percorridos. Revista de
Arqueologia, São Paulo, v. 26/27, n. 1/2, p. 4-15, 2013/2014.

COSTA, Yazid Jorge Guimarães Costa G. Museu, memória e patrimônio: uma trajetória de transformação no Museu do Ceará (1990-1998). Orientador: Marília Xavier Cury. 2012. 223 f. Dissertação (Mestrado em Memória Social) Programa de Pós-Graduação em Memória Social, Universidade Federal do Estado do Rio de Janeiro e Museu de Astronomia e Ciências Afins, Rio de Janeiro, 2012.

\section{EUROPEAN CITIZEN SCIENCE ASSOCIATION} (ECSA). Dez princípios da ciência cidadã. Lisboa: European Citizen Science Association, 2015. Disponível em: https://ecsa.citizen-science.net/ engage-us/10-principles-citizen-science. Acesso em: 6 jan. 2018.

GONÇALVES, José Reginaldo Santos. Coleções, museus e teorias antropológicas: reflexões sobre conhecimento etnográfico e visualidade. Cadernos de Antropologia e Imagem, Rio de Janeiro, n. 8, p. 21-34, 1999.

HOLANDA, Cristina Rodrigues. Museu Histórico do Ceará: a memória dos objetos na construção da História. Fortaleza: SECULT, 2005. (Coleção Outras Histórias, 28).

HOLANDA, Cristina Rodrigues. Museu do Ceará e outras memórias. Entrevista com Valdelice Girão. Fortaleza: SECULT, 2006. (Coleção Outras Histórias, 42).

HOLANDA, Cristina Rodrigues; SABINO, Roberto (Coord.). Museu do Ceará. Série Museus Brasileiros. São Paulo: Banco Safra, 2012.

HITOSHI, Nomura. Um grande naturalista cearense: Francisco Dias da Rocha. Revista do Instituto do Ceará, Fortaleza: 1965. t. 83. p. 224-249.

INSTITUTO DO CEARÁ. Boletim $\mathbf{n}^{\mathbf{0}} \mathbf{4}$ do Instituto do Ceará [dedicado exclusivamente ao museu da entidade]. Fortaleza: Imprensa Oficial do Ceará, 1940. 
JORNAL O ESTADO. Fortaleza, 29 ago. 1941, p. 8 (matéria sem autor).

JORNAL O NORDESTE. Fortaleza, 5 abr. 1934, p. 3. (matéria sem autor).

JORNAL O POVO. Fortaleza, 18 nov. 1937, p. 2 (matéria sem autor).

LANGER, Johnni. Ruínas e mitos. A Arqueologia no Brasil Imperial. Orientador: Ronald Raminelli. 2001. 2014. 327. Tese (Doutorado em História) - Programa de Pós-Graduação em História, Universidade Federal do Paraná, Curitiba, 2001.

MAGALHÃES, Aline Montenegro. Colecionando relíquias. Um estudo sobre a Inspetoria de Monumentos Nacionais (1934-1937). Orientador: Manuel Luiz Lima Salgado Guimarães. 2014. 152 f. Dissertação (Mestrado em História) - Programa de Pós-Graduação em História, Universidade Federal do Rio de Janeiro, Rio de Janeiro, 2004.

MARQUES, Marcélia. Materiais e saber na arte rupestre. Fortaleza: SECULT, 2009. (Coleção Outras Histórias, 58).

MARQUES, Marcélia. A coleção arqueológica do Museu do Ceará: do colecionismo particular ao museológico. In: SAFRA. Catálogo do Museu do Ceará. São Paulo: Safra, 2012. p. 258-261. (Coleção Museus Brasileiros, 23).

MENDONÇA, Rosiane Limaverde Vilar. Arqueologia Social Inclusiva. A Fundação da Casa Grande e a gestão do patrimônio cultural da Chapada do Araripe. Maria da Conceição Lopes . 2016. 528 f. Tese (Doutorado em Arqueologia) Faculdade de Letras da Universidade de Coimbra, Coimbra, 2016.

MORENO, Márcia Rejane Bitu. Museu do Ceará. Relatos da administração de um bem cultural. Orientador: Berenice Abreu de Castro Neves. 1988. 98 f. Monografia (Especialização em Gestão Pública) - Programa de Pós-Graduação em Gestão Pública, Universidade Estadual do Ceará, Fortaleza, 1998.
MUSEU DO CEARÁ. Livro de Tombo (1959). Fortaleza, 1959

MUSEU DO CEARÁ. Fichas de inventário (19592018). Fortaleza, 1959-2018

MUSEU DO CEARÁ. Boletins (1935-1937). Fortaleza, 1937.

MUSEU DO CEARÁ. Guia do Visitante (1960). Fortaleza, 1960.

MUSEU DO CEARÁ. Catálogos (1970-2013). Fortaleza, 1970-2013.

OLIVEIRA, Jacqueline Holanda Tomaz de. Escola Normal do Ceará: $\mathrm{O}$ ensino ativo e a arquitetura do Palacete da Praça Figueira de Melo (1922-1934). Orientador: José Albio Moreira de Sales , 2008. 175 f. Dissertação (Mestrado Acadêmico em Educação) - Programa de Pós Graduação em Educação, Universidade Estadual do Ceará, Fortaleza, 2008.

OLIVEIRA, Márcia Pereira de. Coleção Luiza Ramos: um nordeste imaginado em rendas. Orientador: Nilson Alves de Moraes. 2014. 130 f. Dissertação. (Mestrado em Museologia e Patrimônio) - Programa de Pós Graduação em Museologia e Patrimônio, Universidade Federal do Estado do Rio de Janeiro e Museu de Astronomia e Ciências Afins, Rio de Janeiro, 2015. Disponível em: http://www.repositorio-bc.unirio.br:8080/xmlui/ handle/unirio/12029. Acesso em: 10 dez. 2018.

OLIVEIRA, Ana Amélia Rodrigues de. Juntar, separar, mostrar. Memória e escrita da história no Museu do Ceará (1932-1976). Fortaleza: Museu do Ceará, 2009. (Coleção Outras Histórias, 53).

ORTIZ, Renato. Cultura Brasileira e Identidade Nacional. São Paulo: Brasiliense, 1985.

PASSOS, Marcos Uchoa da Silva. Lendo objetos: a reconstrução do conhecimento histórico no Museu do Ceará. Fortaleza: Museu do Ceará, 2011. (Coleção Outras Histórias, 63).

PORTOALEGRE,M.S.etal.Ascoleçõesindígenasno Museu do Ceará. In: REUNIÃO DA ASSOCIAÇÃO 
BRASILEIRA DE ANTROPOLOGIA, 19., Rio de Janeiro. Anais... Rio de Janeiro: ABA, 1994.

ROCHA, Luiz Carlos Medeiros da. Dos cronistas às pesquisas científicas: algumas informações sobre os materiais líticos polidos do Rio Grande do Norte. Revista Sertões, Mossoró, v. 1, n. 2, p. 33-52, jul./ dez. 2011.

RUOSO, Carolina. Museu do Ceará e a linguagem poética das coisas (1971-1990). Fortaleza: Secretaria da Cultura do Estado, 2009. (Coleção Outras Histórias, 54).

SAMPAIO, Débora Adriano. Vozes do silêncio: memória, representações e identidades no Museu do Ceará. Orientadora: Bernardina Maria Juvenal Freire de Oliveira. 2011. 150 f. Dissertação. (Mestrado em Ciências da Informação) - Programa de Pós-Graduação em Ciências da Informação, Universidade Federal da Paraíba, João Pessoa, 2011.

SANTOS, Paulo César. O Ceará investigado: a Comissão Científica de 1859. Orientador: Francisco Régis Lopes Ramos. 2011. 174 f. Dissertação (Mestrado em História) - Programa de PósGraduação em História, Universidade Federal do Ceará, Fortaleza, 2011.

SCHWARCZ, Lilia Moritz. O espetáculo das raças. Cientistas, instituições e questão racial no Brasil (1870-1930). São Paulo: Companhia das Letras, 1995.
STUDART FILHO, Carlos. Antiguidades indígenas no Ceará. Fortaleza: RIC, 1942.

TELLES, Felipe Bottona da Silva Telles; NOJOSA, Diva Maria Borges. A coleção Dias da Rocha no Museu do Ceará. Fortaleza: Secretaria da Cultura do Estado, 2009. (Coleção Outras Histórias, 60).

VIANA, Verônica; LUNA, Daniel. Arqueologia cearense. Histórico e perspectivas, [s. 1.], p. 2335241, 2018. Disponível em: https://www3.ufpe.br/ clioarq/images/documentos/2002-N15/2002a12. pdf. Acesso em: $10 \mathrm{dez} .2018$.

VIEIRA, Maria Josiane. Itinerários no acervo do Instituto de Antropologia da Universidade do Ceará (1958-1968): a Coleção Arthur Ramos como discurso. Orientador: Luiz Carlos Borges. 2014. 145 f. Dissertação (Mestrado em Museologia) - Programa de Pós-Graduação em Museologia e Patrimônio, Universidade Federal do Estado do Rio de Janeiro, Rio de Janeiro, 2014.

WICHERS, Camila Azevedo de Moraes. Museus e antropofagia do patrimônio arqueológico: (des)caminhos da prática brasileira. Orientadora: Maria Cristina Oliveira Bruno. 2010. 247 f. Tese. (Doutorado em Museologia) - Programa de PósGraduação em Museologia, Universidade Lusófona de Humanidades e Tecnologias, Lisboa, 2010. 